\title{
UMA ANÁLISE CRÍTICA SOBRE QUESTÕES IDEOLÓGICAS A PARTIR DE TWEETS POSTADOS NA CONTA OFICIAL DO PRESIDENTE DO BRASIL, JAIR BOLSONARO
}

José Augusto Simões de Miranda ${ }^{1}$

Otilia Lizete de Oliveira Martins Heinig ${ }^{2}$

\begin{abstract}
Resumo
Este artigo, resultado de uma pesquisa qualitativa, tem como objeto o gênero textual tweet que foi postado na conta oficial do atual presidente da república Jair Bolsonaro, eleito em 2018, em sua rede social Twitter, no ano de 2019. A questão que norteia o estudo é o caráter ideológico dos tweets e sua relação com a (tentativa) de censura. Para que essa análise fosse possível, este trabalho foi embasado nas teorias de LA (Linguística Aplicada) - mais precisamente em seu movimento situado na pós-modernidade - que se caracteriza por um olhar mais crítico, retratado em uma LA indisciplinar, antidisciplinar, transgressiva ou ainda de desaprendizagem. Assim como teorias com questões de ideologia foram discutidas. Os resultados depreendidos sinalizam que o presidente da república repreende vieses ideológicos divergentes daqueles que assume e, portanto, cerceia sujeitos que contestem uma ordem social estabelecida.
\end{abstract}

Palavras-chave: LA. Ideologia. Bolsonaro. Censura. Resistência.

\section{A CRITICAL ANALYSIS REGARDING IDEOLOGICAL ISSUES FROM TWEETS POSTED ON THE OFFICIAL ACCOUNT OF THE PRESIDENT OF BRAZIL, JAIR BOLSONARO}

\begin{abstract}
This article, carried out through a qualitative study, has as its object the genre tweet - which was posted on the official account of the current president of Brazil Jair Bolsonaro, elected in 2018, on his Twitter social network, in 2019. The issue that encompasses the study is the ideological content on the tweets and their relationship to (tentative) of censorship. In order to carry out the analysis, this study was based on the theories of AL (Applied Linguistics) more precisely in its movement situated in the postmodernity - which is characterized by a more critical stance, portrayed in a undisciplinary, antidisciplinary, transgressive, or even unlearning AL. Also, theories that comprehend ideologies were discussed. The overall picture that emerges from the findings of this study reveals that the president rebukes different ideological biases from those ones he presents and, therefore, scolds human subject who challenges a situated social order.
\end{abstract}

Keywords: AL. Ideology. Bolsonaro. Censorship. Resistance.

\section{INTRODUÇÃO}

\footnotetext{
${ }^{1}$ Universidade Federal de Santa Catarina - UFSC, Florianópolis - Santa Catarina, Brasil. Mestre pelo Programa de Pós-Graduação em Inglês da UFSC. Doutorando no Programa de Pós-Graduação em Inglês da UFSC. ORCID $<$ http://orcid.org/0000-0002-0057-1685>.E-mail: joseaugustosimoesdemiranda@gmail.com.

${ }^{2}$ Fundação Universidade Regional de Blumenau - FURB. Doutora em Linguística pelo Programa de PósGraduação em Linguística da UFSC. Professora aposentada do Programa de Pós-Graduação em Educação da FURB. ORCID < http://orcid.org/0000-0001-8234-236X>. E-mail: otilia.heinig@gmail.com.
} 


\section{Linguagens - Revista de Letras, Artes e Comunicação - ISSN 1981- 9943 \\ Blumenau, v. 15, n. 1, p. 146-166, jan./abr. 2021. \\ DOI: http://dx.doi.org/10.7867/1981-9943.2021v15n1p146-166}

Durante as últimas décadas, houve um aumento no uso de tecnologias digitais e sujeitos puderam explorar diversas facilidades que a internet oferece, como vídeos, bate-papo, blogs, fóruns, entre outras, nas quais novas formas de comunicação foram adotadas por meio de diferentes gêneros textuais, para diferentes propósitos e, a expressão de ideias díspares foi acentuada significativamente. Embora isso tenha sido notado de forma mais acentuada durante esse tempo de pandemia, nosso artigo se volta para publicações que a antecedem. $\mathrm{O}$ uso das mídias sociais possibilita que qualquer pessoa seja lida e ouvida, o que é extremamente enriquecedor, pois ainda vivemos numa nação democrática.

Da mesma forma que cidadãos comuns conseguiram expressar suas vozes com maior alcance — por meio das redes sociais, por exemplo — , líderes políticos também acabaram usando esses mesmos gêneros para expor suas opiniões, pensamentos e ideologias. Quando se trata de ideologia, Volóchinov (2018) afirma que toda a palavra carrega um conteúdo ideológico, portanto, a linguagem evidencia a não possibilidade de uma neutralidade ideológica.

Com relação ao atual cenário político e social do Brasil, é possível perceber uma mudança significativa a partir da posse do atual presidente da república, Jair Bolsonaro, eleito em 2018. Trata-se de um governo com um viés ideológico bem mais conservador que os anteriores - pelo menos com relação a um passado próximo. Dessa maneira, observa-se uma maior polarização entre as pessoas em função dessa transposição de poder.

Diante do panorama apresentado, esse artigo busca analisar seis tweets - que foram postados na conta oficial do presidente entre os meses de fevereiro e setembro de 2019 - em sua rede social Twitter. Seu caráter ideológico - que tem como interesse para com determinados grupos e agências, nome usado, neste texto, para instituições como escola, universidade, TV pública — é a base deste estudo.

A fim de situar este estudo em relação aos demais, foi realizada uma busca nos sites Scielo e no Portal de Periódicos da Capes com as palavras "ideologia" e "Bolsonaro" até o final de 2019. Embora se tenham encontrado outros trabalhos que abordassem questões de ideologia com outros objetos que não envolviam o atual governo de Bolsonaro, tão bem como pesquisas sobre o governo do atual presidente da república, mas que não depreendiam questões de ideologia, não se achou relevante citá-los, visto que o objetivo desse trabalho é analisar questões de ideologia que são representadas pelos tweets postados na conta oficial de Bolsonaro. Dessa forma, diante do panorama sociopolítico com o qual o país se depara - em que o atual governo demonstra repreender vieses ideológicos de determinados grupos, que 


\section{Linguagens - Revista de Letras, Artes e Comunicação - ISSN 1981- 9943 \\ Blumenau, v. 15, n. 1, p. 146-166, jan./abr. 2021. \\ DOI: http://dx.doi.org/10.7867/1981-9943.2021v15n1p146-166}

serão abordados posteriormente — sugerem-se, em caráter de urgência, discussões sobre questões ideológicas que são relacionadas com (tentativas de) censuras e, portanto, depreende-se a relevância dessa pesquisa.

Para isso, primeiramente, diferentes movimentos da LA (Linguística Aplicada) são situados - como pedagogia do ensino de língua estrangeira; diálogos com outras áreas de conhecimento em um contexto interdisciplinar; e uma LA indisciplinar, antidisciplinar, transgressiva ou ainda de desaprendizagem, que se caracteriza por um viés mais crítico. Posteriormente, questões de ideologias com seus movimentos históricos são discutidos.

\section{FUNDAMENTAÇÃO TEÓRICA}

\subsection{OS MOVIMENTOS DA LINGUÍSTICA APLICADA}

Partindo de um pressuposto histórico, Moita Lopes (2009) afirma que, a partir de 1940 - durante a segunda guerra mundial - teve o nascimento da LA (Linguística Aplicada), assim como o surgimento de materiais para o ensino da língua. Portanto, percebe-se que, nesse primeiro momento, a LA era usada estritamente em contextos de ensino e aprendizagem da língua e, mais especificamente, o inglês como língua estrangeira. Menezes, Silva e Gomes (2009) afirmam que, com a aplicação da linguística para Linguística Aplicada em uma pedagogia de ensino da língua estrangeira, houve, paralelamente, um consenso com a preocupação da LA como prática social, seja com língua materna ou língua adicional.

Num segundo momento, Menezes et al. (2009) apontam que é possível perceber as conversas da LA em outros contextos - incluindo diferentes áreas da ciência, como a Sociologia, a Filosofia, a Psicologia, a Pedagogia, a Antropologia, a Geografia, entre outras. Moita Lopes (2006) afirma que essa segunda virada da LA pode ser vista com maior realce no Brasil. O autor afirma que ao contrário de outros países, a LA expandiu o seu cerne de interesse - com estudos que eram restritos para o ensino e aprendizagem de língua estrangeira - para diferentes contextos e, dessa forma, atendendo um panorama interdisciplinar. Signorini (1998) complementa que, diante desses contextos distintos e específicos de uso da linguagem, a LA, seu campo epistemológico e suas práticas não têm como ser neutros de valores. A partir dessa pluralidade situacional, inevitavelmente, haverá a necessidade de olhares distintos para a linguagem.

Enquanto as viradas anteriores se situam na modernidade, uma terceira virada é vista na pós-modernidade sendo possível perceber uma transição da LA interdisciplinar — essas 


\section{Linguagens - Revista de Letras, Artes e Comunicação - ISSN 1981- 9943 \\ Blumenau, v. 15, n. 1, p. 146-166, jan./abr. 2021. \\ DOI: http://dx.doi.org/10.7867/1981-9943.2021v15n1p146-166}

conversas com outras áreas, como citadas anteriormente - para uma LA indisciplinar, antidisciplinar, transgressiva ou ainda de desaprendizagem; termos que podem variar entre teóricos da área. Enquanto a LA associada à modernidade observa a linguagem descontextualizada com um sistema de regras prescritivas, que advém do movimento positivista, e, portanto, ignora qualquer tipo de ideologia, a LA pós-moderna desafia hegemonias que são formadas por discursos dominantes (KUMARAVADIVELU, 2006).

Nessa perspectiva, Lyotard (2018) destaca que o saber pós-moderno estimula a sensibilidade de sujeitos para diferenças e injustiças sociais e oferece ferramentas para lidar com essas questões de uma forma emancipatória. É importante salientar que, como sujeitos críticos, racionais e conscientes - que podem ser provenientes do conhecimento científico depreende-se uma maior preparação para contestar e obter a libertação daquilo que é imposto, mediados por discursos fabricados e autoritários. Dessa forma, a luta contra a alienação possibilita a superação de uma verdade unilateral, assim como oferece recursos para que a liberdade seja conquistada (DUARTE; MARTINS, 2013).

Em relação à ciência e à ideologia, Rajagopalan (2003) afirma que um posicionamento político-ideológico pode ser plenamente compatível com a ciência. O autor explica que, diferentemente de Ciências Exatas e Biológicas, as Ciências Sociais e Humanas podem conter um cunho ideológico atrás de reflexões científicas, ou seja, há uma linha tênue entre ciência e ideologia, teoria e mitologia, razão e não senso (RAJAGOPALAN, 1998). Assim, novos horizontes; que perpassam um princípio de "neutralidade ideológica"; serão almejados.

Nessa mesma linha, Moita Lopes (2009) destaca a importância de formas de pesquisa sem uma separação com a política, pois, dessa forma, a tematização para o que não é tematizado é a possibilidade de dar voz a quem não tem. De acordo com Rajagopalan (2003), uma linguística eticamente compromissada estará ao alcance de sujeitos, desde que tenham uma visão crítica diante de seus novos princípios. Por meio dessa ciência - mais especificamente a LA — serão fornecidas ferramentas para que seja possível analisar e promover uma reflexão crítica, no sentido de construir um espaço social mais democrático, cuja ideologia seja estabilizar o poder entre o todo.

A partir desse viés pós-moderno da LA, Moita Lopes (2006) afirma que, ao invés de solucionar problemas, a LA procura problematizá-los ou criar inteligibilidades e, dessa forma, outros contextos para o uso da linguagem podem ser alcançados, fazendo com que a LA torne-se nômade ou mestiça. É possível notar uma abordagem mais crítica, em que problemas no uso da linguagem serão analisados, inevitavelmente, em seus diferentes contextos socioculturais, políticos e históricos. 


\title{
Linguagens - Revista de Letras, Artes e Comunicação - ISSN 1981- 9943 \\ Blumenau, v. 15, n. 1, p. 146-166, jan./abr. 2021. \\ DOI: http://dx.doi.org/10.7867/1981-9943.2021v15n1p146-166
}

Partindo da premissa de que a LA depreende uma perspectiva mais crítica, Geraldi (2010) afirma que a linguagem oferece trajetórias individuais que sujeitos sociais e heterogêneos possam experimentar. Ele aponta que, devido a essa divergência de construções que a linguagem proporciona como uma atividade constitutiva, há uma gama de possibilidade para a compreensão de outros horizontes - em que sujeitos críticos, racionais e conscientes estão inseridos. Assim, mediante o exercício de cidadania e o pensamento humanista, empenha-se para que diferenças sejam respeitadas e desigualdades sejam suprimidas.

Percebe-se que, na busca por uma transformação, sujeitos estão expostos a riscos, pois estão contestando a manutenção de uma ordem social estabelecida. Desse modo, estudiosos com uma concepção mais crítica podem se deparar com uma área perigosa - no sentido de serem perseguidos e/ou ameaçados — pois, paradoxalmente, enquanto eles convidam sujeitos a refletir e a olhar para o mundo de outra forma, estão de frente a um "campo de batalha", em que outros sujeitos podem atacá-los de diferentes formas - como interpretá-los erroneamente com os mais diversos tipos de distorções daquilo que realmente propunham (MOITA LOPES, 2009).

Todo esse cerceamento feito a sujeitos em busca de mudanças de sociedades mais justas é percebido ao longo da história em um processo contínuo:

\begin{abstract}
Ao educador crítico cabe a tarefa de estimular a visão crítica dos alunos, de implantar uma postura crítica, de constante questionamento das certezas que, com o passar do tempo, adquirem a aura e a 'intocabilidade' de dogmas. É por este motivo que o educador crítico atrai, via de regra, a ira daqueles que estão plenamente satisfeitos com o status quo e interpretam qualquer forma de questionamento das regras do jogo estabelecidas como uma grave ameaça a si e à sua situação confortável e privilegiada. A história vem se repetindo desde longínquos tempos na Grécia Antiga, quando Sócrates, o pai da filosofia no mundo ocidental, foi obrigado a se retratar de tudo o que ensinara aos atenienses sob pena de pagar pelo crime de perturbar a ordem com a sua própria vida. $\mathrm{O}$ educador crítico sempre foi e sempre será uma ameaça para os poderes constituídos (RAJAGOPALAN, 2003, p.111-112)
\end{abstract}

Portanto, diante de todo esse cenário de ameaças e punições a sujeitos críticos como já vimos comumente ao longo da história, desde a Grécia Antiga até recentes regimes ditatoriais, como o golpe militar de 1964 - diferentes tipos de discursos — fabricados, autoritários, homogêneos, infundados, estereotipados e preconceituosos - são constantemente empenhados para que sejam aplicados. Com esses ideais de construções de sujeito, Moita Lopes (2006) ressalta que há um apagamento na história - classe social, gênero, orientação sexual, raça, etnia, entre outras — de todos os sujeitos que não pertencem a esse padrão. 


\section{Linguagens - Revista de Letras, Artes e Comunicação - ISSN 1981- 9943 \\ Blumenau, v. 15, n. 1, p. 146-166, jan./abr. 2021. \\ DOI: http://dx.doi.org/10.7867/1981-9943.2021v15n1p146-166}

A homogeneização da história e práticas discursivas de sujeitos, que foram mencionadas anteriormente, pode gerar um questionamento sobre a depreensão dessa marginalização perante alguns grupos. Como Pennycook (2006) sugere, ninguém é obrigado a concordar com ninguém; mas antes de argumentar, é essencial compreender as questões em pauta e não simplesmente ignorá-las e atacá-las sem fundamento algum.

Ademais, segundo Fabricio (2006), essa "mudança de rumo" que a LA promove não trará soluções prontas, tampouco imediatas para salvar indivíduos que não foram privilegiados; entretanto, viabiliza novas formas de percepção e organização da sociedade perante círculos históricos viciados. Desse modo, suas teorias críticas - por meio da disseminação de pesquisas - apresentam contribuições relevantes para um processo de transformação de práticas discursivas e sociais que são causadoras do sofrimento humano.

\subsection{QUESTÕES DE IDEOLOGIA}

Quando se trata de questões ideológicas, é possível observar diferentes vieses ao próprio termo, que muda em decorrência de fatores históricos e, dessa forma, teóricos podem divergir em suas concepções epistemológicas. Löwy (2000) afirma que as visões sociais do mundo se diferenciam entre ideologia - que possui um caráter mais conservador de manutenção de uma ordem social previamente estabelecida - e utopia - que é caracterizada por um caráter mais crítico em busca de uma realidade ainda não existente e se contradiz com essa ordem social estabelecida. Ele ainda destaca importantes movimentos ${ }^{3}-$ dentre eles o Positivismo, o Historicismo e o Marxismo.

Com relação ao primeiro movimento, o autor afirma que o positivista acredita que as metodologias das Ciências Sociais devem ser idênticas às metodologias das Ciências Naturais — objetivas, neutras, livres de quaisquer ideologias e visões de mundo —, pois o funcionamento da sociedade é regido pelas mesmas leis do tipo da natureza. Entretanto, o cientista social se depara com questões sociais que, inevitavelmente, são carregadas de ideologias. Há uma história do Barão de Münchhausen que exemplifica essa tentativa de neutralidade. Ele estava com seu cavalo quando começou a afundar em um pantanal e, no momento em que estava quase na altura do ventre do cavalo, o barão se desespera e tem uma ideia genial: puxa seus próprios cabelos até tirar seu corpo e depois o cavalo, do pantanal, num salto repentino (LÖWY, 2015). O autor mostra que essa analogia realça que sujeitos

\footnotetext{
${ }^{3}$ Segundo Löwy (2015), essas correntes filosóficas podem dialogar; ou seja, há vertentes científicas que podem ser, paradoxalmente, positivistas e historicistas ou historicistas e marxistas, por exemplo.
} 


\section{Linguagens - Revista de Letras, Artes e Comunicação - ISSN 1981- 9943 \\ Blumenau, v. 15, n. 1, p. 146-166, jan./abr. 2021. \\ DOI: http://dx.doi.org/10.7867/1981-9943.2021v15n1p146-166}

estão enterrados em suas ideologias e a tentativa de puxar seus próprios cabelos para que sejam ideologicamente neutros é, portanto, falha por não reconhecerem tal situação — de preconceitos, visões sociais do mundo e estereótipos.

Com relação ao historicismo, Löwy (2015) argumenta que ele é visto em qualquer fenômeno social, cultural ou político relativo e dependente da história e, sendo assim, existe uma diferença significativa entre os fatos histórico e social; e o natural. $\mathrm{O}$ autor também destaca que o historicista reconhece uma diferença entre os tipos de ciência; enquanto nas Ciências Sociais, o homem estuda a si mesmo - como um sujeito e objeto cultural - e isso implica em uma dificuldade de um distanciamento; as Ciências Naturais estudam um objeto completamente exterior - como a órbita da lua ao redor da terra. Porém, por se tratar de um movimento de relativismo histórico, percebe-se que ele compreende um caráter limitado, ou seja, de conservação daquilo que já foi constituído ao longo de anos, décadas, séculos ou milênios.

Por outro lado, o marxismo enfoca na luta de classes para uma transformação de mundo numa perspectiva humanizadora. Esse movimento depreende que uma tentativa de "neutralidade" de diferentes tipos de classes dominantes sobre classes dominadas está ligada a interesses de manutenção de poder, ou seja, não há como ter neutralidade em questões ideológicas, pois conforme já citado, mesmo que sujeitos não se manifestem diante de alguma coisa, já deixam de ser neutros, favorecendo, de alguma forma, aquela ordem estabelecida ao invés de questioná-la e buscar uma transformação (LÖWY, 2015). Dessa forma, ao apontar uma pseudoneutralidade no estudo das Ciências Sociais, o marxismo busca uma igualdade de direitos e valoração entre indivíduos, a fim de que uma ordem social democrática e humanista prevaleça.

A pseudoneutralidade discutida nos parágrafos anteriores pode levar a reflexões pertinentes — da não alienação e do estímulo da criticidade. A partir dessa visão crítica, Lessa e Tonet (2011) levantam o seguinte questionamento: é possível uma real mudança e reação a uma ordem estabelecida por ser injusta e desigual? Os autores afirmam que, numa visão conservadora de mundo, a resposta, certamente, seria um não, ou seja, as organizações e visões sociais são imutáveis, pois carregam um longo e pesado fator histórico e, dessa forma, somente nos cabe aceitar o que se conserva ao longo do tempo.

No entanto, os revolucionários sugerem uma utopia — que se trata de ideias contrárias à aceitação do status quo —, portanto almejam algo ainda não conquistado a fim de resistir e buscar uma ruptura numa visão subversiva e crítica do mundo (LÖWY, 2015). Isso está ligado ao exercício da atenção consciente, reflexiva e coletiva. Assim, percebe-se que um olhar atento e 


\title{
Linguagens - Revista de Letras, Artes e Comunicação - ISSN 1981- 9943 \\ Blumenau, v. 15, n. 1, p. 146-166, jan./abr. 2021. \\ DOI: http://dx.doi.org/10.7867/1981-9943.2021v15n1p146-166
}

humanizador sobre o outro - especialmente aqueles que têm suas "identidades" negadas e suas vozes abafadas - é primordial para que prevaleça uma existência igualitária.

Para a perspectiva enunciativa, o homem social está cercado de fenômenos e produtos ideológicos que perpassam palavras, símbolos, crenças, obras de artes etc.

\begin{abstract}
Qualquer produto ideológico é não apenas uma parte da realidade natural e social seja ele um corpo físico, um instrumento de produção ou um produto de consumo mas também, ao contrário desses fenômenos, reflete e refrata outra realidade que se encontra fora dos seus limites. Tudo que é ideológico possui uma significação: ele representa e substitui algo encontrado fora dele, ou seja, ele é um signo. Onde não há signo também há ideologia. Pode-se dizer que um corpo físico equivale a si próprio: ele não significa nada e coincide inteiramente com a sua realidade única e natural. Nesse caso, não temos como falar de ideologia (VOLÓCHINOV, 2018, p. 91-92)
\end{abstract}

Dessa forma, ao observar e apreciar uma obra de arte, por exemplo, ela por si só pode não representar um produto ideológico, mas a imagem que ela representa criará esse produto ideológico. Assim, Volóchinov (2018) explica que diferentes tipos de objetos de tecnologia ou de consumo podem se transformar em um signo e, por conseguinte, geram um significado que ultrapassa os limites de sua existência neutra. Porém, conforme o autor ainda argumenta, tais signos e significados não são únicos e universais; em outras palavras, há a possibilidade de distorção, de percepção sob um determinado ponto de vista e, portanto, as categorias ideológicas (bom, mal, certo, errado, verdadeiro, falso, justo, injusto etc.) podem ser avaliadas em qualquer signo.

Com relação à linguagem, Volóchinov (2018) afirma que ela é o exemplo mais claro e pleno como função de signos, pois toda palavra carrega um conteúdo ideológico e, sendo assim, a linguagem está em primeiro plano da ciência das ideologias; não é indissolúvel e nem tem como ser separada de seu conteúdo ideológico. Conforme já discutido anteriormente, a questão da neutralidade ideológica não pode ser vista na linguagem. Nossas concepções de mundo e crenças, portanto, se tornam uma realidade ideológica a partir da linguagem (MEDVIÉDEV, 2012).

Partindo do pressuposto marxista em que a ideologia (ou utopia) seja uma maneira de pensar, dentro de um campo intelectual, com base nas experiências e crenças culturais, sociais, políticas de um sujeito, é possível afirmar que ela é uma parte das "verdades" dessas pessoas ou desses grupos (LÖWY, 2000). O autor sugere que tais pessoas ou grupos podem ter representantes - com seus distintos vieses ideológicos - nessas diferentes esferas intelectuais - políticas, literárias, científicas etc. 


\section{Linguagens - Revista de Letras, Artes e Comunicação - ISSN 1981- 9943 \\ Blumenau, v. 15, n. 1, p. 146-166, jan./abr. 2021. \\ DOI: http://dx.doi.org/10.7867/1981-9943.2021v15n1p146-166}

\section{METODOLOGIA}

Como explicado anteriormente, o presente artigo visa analisar seis tweets, postados na conta oficial do presidente entre os meses de fevereiro e setembro de 2019, em sua rede social Twitter. O critério de seleção foi baseado naqueles que apresentavam caráter de (tentativas) de censura. A organização para análise foi feita através da seguinte ordem de agências criticadas: escola/universidade (educação); órgão de pesquisas (CONAD); instituições públicas (Banco do Brasil, TV pública). Os grupos comentados foram respectivamente: professores; atores educacionais (professores, alunos); alunos; membros da sociedade civil; minorias raciais e sexuais.

O caráter ideológico das publicações, suas agências e interlocutores orientam a seleção e análise dos enunciados. A pesquisa de caráter qualitativo recorre às teorias de linguística aplicada e análise dialógica do discurso para a análise dos dados.

O Twitter é uma rede social — criada em 2006 — que tem como slogan "o que está acontecendo?". Dessa forma, seus usuários podem fazer postagens e ver outras postagens sobre opiniões, serviços, produtos, por meio de comentários, realizado pelo gênero textual tweet. Para ser um usuário, há a necessidade de um cadastro - que é feito gratuitamente.

O enunciado oral, escrito ou com usos de outros recursos semióticos se materializa em um gênero textual que, além das suas distintas dimensões, está relacionado com as práticas de linguagem e a situação de comunicação a qual, segundo Rojo (2005) envolve a esfera comunicativa, o tempo e o lugar históricos, as relações sociais dos participantes, a apreciação valorativa e a modalidade de linguagem ou mídia. Nesse artigo, consideraram-se todos esses aspectos no que tange ao gênero textual tweet para que se possam compreender as relações que são construídas em seu uso.

O tweet é um gênero emergente na mídia textual, é um hipertexto e a ele podem estar vinculados diferentes links que dialogam com outros gêneros como notícia, reportagem, vídeo. Pode-se, nessa perspectiva, também aproximar o tweet de um suporte para outros gêneros. A origem desse gênero está em outro, o blog, caracterizando uma intergenerecidade. Segundo Greenhow e Gleason (2012), o twitter modificou e ressignificou o blog, alterando, principalmente, a organização composicional, limitando o número de caracteres a 140, por isso ele passou a ser chamado de microblog. Em síntese, pode-se afirmar que o tweet é um gênero escrito, podendo incluir recursos semióticos, que é produzido por textos curtos, em linguagem informal e usado por uma população heterogênea. 
Na próxima seção, serão analisados dentro da esfera política, os seis tweets que foram postados na conta oficial do atual presidente da república Jair Bolsonaro, em 2019.

\section{RESULTADOS}

Partindo da premissa da inexistência de neutralidade em questões ideológicas e da resistência de uma ordem social por discursos dominantes, nesta seção, são analisados seis tweets - caracterizados pelo discurso político de Bolsonaro.

O discurso político constitui-se por espaços de enunciação clássicos — que acontecem nos legislativos federais, estaduais e municipais, no executivo, nas palavras de diferentes governantes, como o presidente da república, governadores e prefeitos - e é caracterizado por uma tentativa de sustentar sentidos em cenários de disputa (PINTO, 2006). A autora afirma que uma característica fundamental desse tipo de discurso é a imposição de uma verdade - muitas vezes unilaterais - para que consigam sobreviver e possíveis ameaças se diluem.

Apesar de o discurso político ser muito comum em períodos de campanhas eleitorais e, dessa forma, caracterizado por um viés eleitoral, esse tipo de discurso é também deduzido durante o exercício de poder, criado para diferentes propósitos, como uma possível reeleição, por exemplo. Ainda, é possível perceber o caráter (anti)democrático no discurso político, que pode variar de acordo com os vieses ideológicos de um governo e suas intencionalidades.

Em seu discurso, nos tweets postados, o presidente criticou em três deles a agência escola/universidade; em um deles, um órgão de pesquisas - CONAD (Conselho Nacional de Políticas sobre Drogas); em dois deles, a agência instituição pública — Banco do Brasil e TV pública. Com relação aos grupos repreendidos no corpus analisado, um dos grupos é formado por professores; dois por estudantes; e um por membros da sociedade civil — médico; psicólogo; enfermeiro; educador; cientista; estudante e dois foram minorias — raciais e sexuais. A análise dos tweets está organizada a fim de que as agências e os grupos dialoguem entre si para que se depreenda a aproximação dos discursos em diferentes enunciados, sinalizando um discurso de repressão.

Figura 1. Tweet postado em 28 de abril de 2019 


\section{Linguagens - Revista de Letras, Artes e Comunicação - ISSN 1981- 9943 \\ Blumenau, v. 15, n. 1, p. 146-166, jan./abr. 2021. \\ DOI: http://dx.doi.org/10.7867/1981-9943.2021v15n1p146-166}

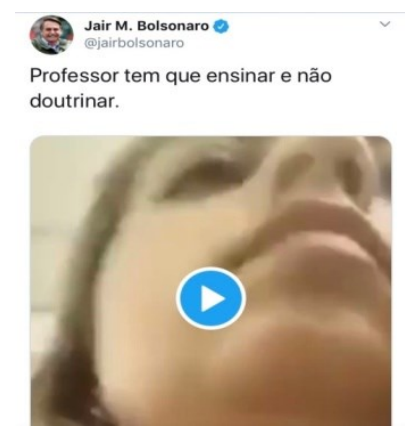

Fonte: Twitter

$\mathrm{Na}$ Figura 1, o presidente critica a agência escola e o grupo professores. Além da postagem feita pela sua conta, é mostrado um vídeo de uma aluna, em um cursinho prévestibular, gravando a aula - em que a professora critica o astrólogo Olavo de Carvalho. A aluna diz "eu não estou pagando cursinho para ouvir a sua opinião política-partidária, eu tô pagando cursinho para assistir aula de gramática". Dessa forma, há dois sujeitos que partilham do mesmo víes ideológico, que é aqui analisado.

Quando o presidente afirma "tem que ensinar", é depreendido um caráter autoritário em seu discurso político, sinalizando uma obrigatoriedade, como se ele fosse responsável por determinar o que a categoria docente deva fazer em suas aulas. $\mathrm{O}$ segundo ponto está na expressão "e não doutrinar". Aqui há uma negação com sentido pejorativo — a palavra "doutrinar" - gerando uma possível generalização diante de sua audiência — como se professores não ensinassem os conteúdos propostos em seus planos de ensino e, ao invés disso, inculcassem crenças e atitudes em seus alunos, homogeneizando-os na forma de pensar e falar. De acordo com Rajagopalan (2003), a ciência pode, perfeitamente, conciliar-se com um posicionamento político-ideológico. Portanto, a premissa de "doutrinação" — em seu sentido pejorativo - que o presidente afirma, é infundada.

Com relação ao vídeo postado, quando a aluna afirma "eu tô pagando cursinho para assistir aula de gramática", ela se coloca em posição de cliente, pois quer escolher o que aprender. Ao optar pela palavra "assistir", é possível depreender um caráter de espectadora, ao invés de participante que se soma ao de cliente com relação ao processo de ensinoaprendizagem.

A Constituição Federal, aprovada em 1988, garante "liberdade de aprender, ensinar, pesquisar e divulgar o pensamento, a arte e o saber" e "pluralismo de ideias e de concepções pedagógicas, e coexistência de instituições públicas e privadas de ensino" (BRASIL, [2016]). Além disso, "são invioláveis a intimidade, a vida privada, a honra e a imagem das pessoas, assegurado o direito a indenização pelo dano material ou moral decorrente de sua violação" 
(BRASIL, [2016]). Dessa forma, a filmagem em sala de aula sem a autorização prévia do docente não é permitida e a repreensão autoritária do presidente é contrária a legislação.

Quanto ao conteúdo da postagem que fez o presidente compartilhar sua indignação em sua rede social, a professora estava criticando um astrólogo, com o qual o presidente tem uma relação próxima, tão bem como um viés ideológico convergente - conservador e autoritário. Sujeitos críticos que, de alguma forma, questionam o status quo, podem correr riscos, pois, muitas vezes, são interpretados de outra forma por indivíduos que tentam repreendê-los (MOITA LOPES, 2009). Desse modo, Bolsonaro desaprovou, por meio desse tweet, a fala da professora, por ter um viés ideológico divergente daquele que conserva em seu discurso político, o qual se caracteriza pela imposição de uma verdade (PINTO, 2006).

Figura 2. Tweet postado em 6 de fevereiro de 2019

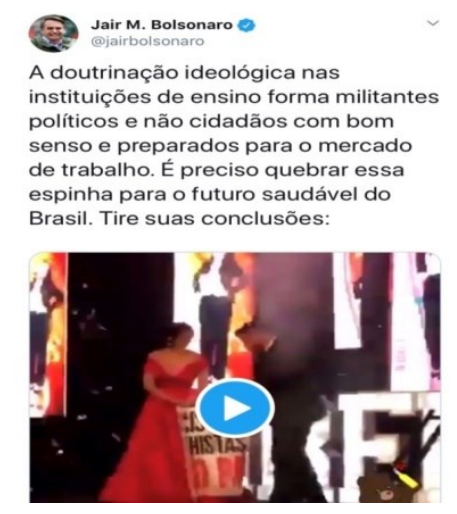

Fonte: Twitter

A agência criticada na Figura 2 é a universidade e o grupo são atores educacionais. Com relação ao vídeo - que foi repostado por Olavo de Carvalho - observa-se uma tentativa de analogia ao comunismo por conter uma faixa segurada por estudantes escrita "fascistas, racistas, machistas e homofóbicos não passarão". Os termos "fascistas, racistas, machistas e homofóbicos", na sentença, são, sintaticamente, sujeito e, morfologicamente, substantivos, pois a intenção, nesse enunciado, é elencar os grupos. Segundo Neves (2011, p. 175, grifo do autor), "um substantivo pode deixar de ser referencial e funcionar como se fosse um adjetivo. [...] atuar como qualificador ou como classificador", e isso se observa na materialidade linguística analisada.

No enunciado em questão, a qualificação dos sujeitos é que sinaliza a sua exclusão. Ademais, depreende-se a manutenção de uma ordem estabelecidada, a fim de que as classes citadas na faixa - oposição, negros, mulheres, LGBT — não tenham voz, tampouco haja uma ruptura na tentativa de transformação e compreensão de novos olhares - nos quais 


\section{Linguagens - Revista de Letras, Artes e Comunicação - ISSN 1981- 9943 \\ Blumenau, v. 15, n. 1, p. 146-166, jan./abr. 2021. \\ DOI: http://dx.doi.org/10.7867/1981-9943.2021v15n1p146-166}

almejam o prevalecimento de uma sociedade humanizadora. Geraldi (2010) explica que diante da linguagem, podemos expandir nossas percepções e, portanto, nos permite sermos cidadãos conscientes e críticos; a fim de que o respeito preconize e as diferenças - étnicas, raciais, sexuais, entre outras — sejam excluídas.

Com relação à postagem, novamente (como no tweet anterior), o presidente fala em "doutrinação" (ideológica) nas instituições de ensino. Primeiramente, quando ele afirma "e não cidadãos com bom senso para o mercado de trabalho", desaprova sujeitos que busquem combater diferentes tipos de preconceitos, pois são militantes políticos e têm um viés ideológico não condizente com o mercado de trabalho, tornando-os inaptos para esse exercício. Além disso, uma ameaça é depreendida em "é preciso quebrar essa espinha", pois se trata de uma metáfora para uma ruptura definitiva. Há, portanto, uma dicotomia entre "cidadãos com bom senso", que representam um "futuro saudável" e "militantes políticos" que não representam um "futuro saudável”, mas sim doentio.

Como sujeitos críticos e racionais com um olhar sensível diante de injustiças sociais, há espaços nos quais o saber pós-moderno - que pode ser fundamentado no conhecimento científico - é incentivado e oferece ferramentas para uma posição de resistência - em que a coletividade predomina, fortalecendo a busca de uma transformação para resultados efetivos (LYOTARD, 2018).

Figura 3. Tweet postado em 6 de setembro de 2019

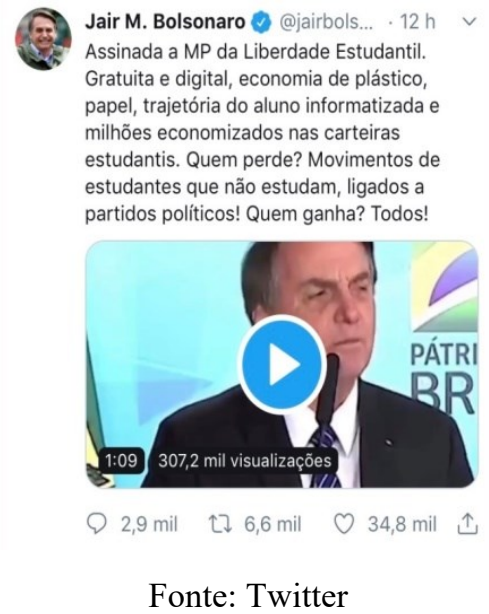

Na Figura 3, novamente, a agência criticada é a escola/universidade e o grupo são estudantes, indicando a manutenção de um discurso contra instituições de ensino. Quando Bolsonaro afirma "liberdade estudantil" e em seguida "trajetória do aluno informatizada", é 


\section{Linguagens - Revista de Letras, Artes e Comunicação - ISSN 1981- 9943 \\ Blumenau, v. 15, n. 1, p. 146-166, jan./abr. 2021. \\ DOI: http://dx.doi.org/10.7867/1981-9943.2021v15n1p146-166}

possível notar um antagonismo, pois, ao seguir "a trajetória do aluno informatizada", depreende-se um controle do sujeito e seu caminho que, portanto, não condiz com liberdade.

O presidente também pergunta: “Quem perde?”. E, imediatamente, responde: "movimentos de estudantes que não estudam, ligados a partidos políticos!”. Nesse trecho, Bolsonaro faz uma correlação de estudantes com malandragem, ociosidade e partidos políticos - em que há uma relação metonímica de parte pelo todo, ou seja, partidos políticos de esquerda. Ao construir a resposta curta "todos!", faz uso do pronome indefinido o qual é núcleo do sintagma, funcionando, nesse caso, como um pronome adjetivo (NEVES, 2011). Tem-se uma adjetivação positiva de um lado, que aponta para os não incluídos no grupo citado no texto, e uma negativa do outro que reforça a ideia de malandragem.

No texto desse tweet, depreende-se que Bolsonaro exclui estudantes os quais ele afirma estarem "ligados a partidos políticos". Isso caracteriza um discurso político em que se elabora uma disputa entre "estudantes ligados a partidos políticos" — que o presidente afirma que não estudam - e "todos" - demais sujeitos que ele agrega, partindo da premissa que apresentam um caráter ideológico de acordo com que ele preconiza nesse cenário.

A universidade é um ambiente de interação social e reflexão crítica em que a pluralidade de ideias e pensamentos divergentes é incentivada. Assim, para que seja possível conquistar uma posição de cidadãos emancipados, livres e autônomos; a luta contra a alienação é fundamental, pois ela oferece ferramentas para um olhar distinto sobre o outro dos quais verdades parciais são contestadas (DUARTE; MARTINS, 2013). Entretanto, é possível notar que Bolsonaro repudia sujeitos que fazem parte dessa agência por, comumente, resistirem a uma ordem social estabelecida. Assim, o presidente da república tenta instituir para que as pessoas pensem uniformemente, de acordo com a ideologia que ele determina que seja correta, verdadeira e do bem, retratando uma verdade unilateral e cerceada.

Figura 4. Tweet postado em 22 de julho de 2019

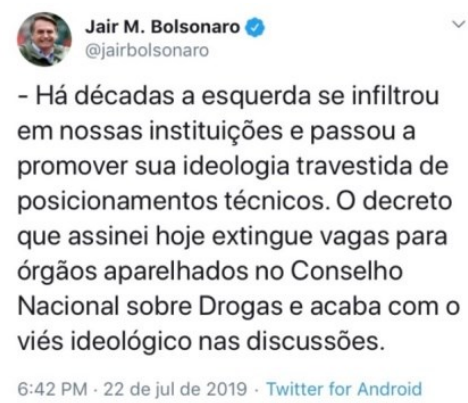

Fonte: Twitter 
$\mathrm{Na}$ Figura 4, a agência punida foi um órgão de pesquisas. O grupo extinto foram membros da sociedade civil que compunham o CONAD — um jurista, um médico, um psicólogo, um enfermeiro, um educador, um cientista e um estudante. Assim, o presidente tenta manter representantes do governo que comunguem de suas ideias. O texto do tweet indica a extinção de sujeitos ligados à categoria científica - que têm conhecimento especializado e fundamentado em suas respectivas áreas - por ameaçarem uma oposição que ignora fundamentos científicos.

O uso dos termos "infiltrar" e "travestido" sinalizam a não legitimidade de pertencimento a esse grupo "oficial". A justificativa se dá por serem de "esquerda", assim, mais uma vez foi mantido um discurso dualista de ideologia. Inicialmente, o sujeito na posição de presidente de república afirma a existência de ideologia — travestida — para depois negar - quando ele afirma "e acaba com o viés ideológico". O poder do enunciador, na tomada de decisões, é depreendido também pelo uso de "extingue" e "acaba", semanticamente próximos, indicando o sentido de anulação. Como afirma Pinto (2006, p. 11), "todo o discurso é um discurso de poder, na medida em que todos os discursos pretendem impor verdades a respeito de um tema específico ou de uma área da ciência, da moral, da ética, do comportamento", entretanto, o discurso político evidencia essa posição de poder pelo posicionamento que o locutor assume.

Outro ponto relevante é o da relação harmoniosa entre a ciência e um posicionamento político-ideológico, em que Rajagopalan (1998) difere as Ciências Sociais e Humanas das Exatas e Biológicas. O autor explica que, atrás das reflexões científicas (ou técnicas), é perfeitamente cabível haver um cunho ideológico, pois há uma linha tênue entre ciência e ideologia e, portanto, não há como desassociá-las.

Figura 5. Tweet postado em 21 de agosto de 2019

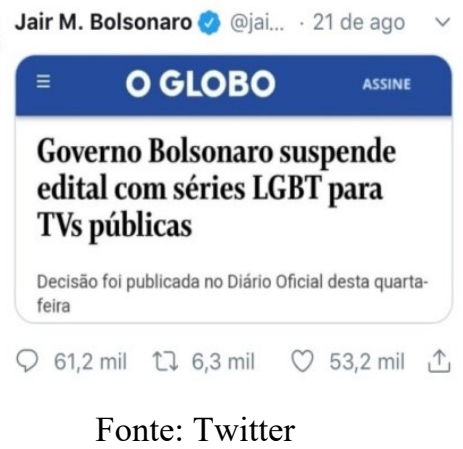




\section{Linguagens - Revista de Letras, Artes e Comunicação - ISSN 1981- 9943 \\ Blumenau, v. 15, n. 1, p. 146-166, jan./abr. 2021. \\ DOI: http://dx.doi.org/10.7867/1981-9943.2021v15n1p146-166}

Na Figura 5, a agência censurada são as TVs públicas e o grupo é a população LGBT. Embora seja de um jornal, é uma notícia de uma decisão tomada - que foi publicada no Diário Oficial - por um viés ideológico caracterizado pelo conservadorismo, preconceito, ignorância e a não aceitação de uma diferente forma de pensar, agir, se comportar e ser.

Primeiramente, trata-se de um discurso citado - representado por Bolsonaro - que mostra concordância e, dessa forma, valida a ação, pois a torna pública. Há uma modalização na manchete quando se tem o verbo "suspender", ao invés de acabar. Quando a manchete menciona "governo", depreende-se uma relação metonímica, pois, na realidade, a decisão foi feita pelo presidente da república. Ainda é possível notar a censura em uma parcela das emissoras - representada pelas TVs públicas — das quais o presidente detém controle.

É importante ressaltar que o uso do léxico "governo" é uma característica do discurso político. Esse tipo de discurso depreende-se pela defesa de posicionamentos que perpassam por um viés ideológico partidário (STORTO; ZANARDI, 2019). Embora o presidente já esteja eleito, há um viés eleitoral e autoritário em seu discurso político, em que congrega sujeitos com as mesmas idiossincrasias que ele defende e preconiza em seu governo.

Esse viés ideológico - caracterizado pela intolerância e preconceito de uma classe dominante - oprime, cerceia, humilha a existência de uma classe dominada — refletida em uma minoria sexual - pois, de alguma maneira, há uma tentativa de identidade apagada. No que diz respeito a esse apagamento, Moita Lopes (2006) afirma que esse fato é comum ao longo da história a diferentes grupos minoritários - classe social, gênero, orientação sexual, raça, etnia etc. - por não pertencerem ao padrão normativo hegemônico. Sendo assim, é conveniente a sua extinção.

Figura 6. Tweet postado em 4 de maio de 2019

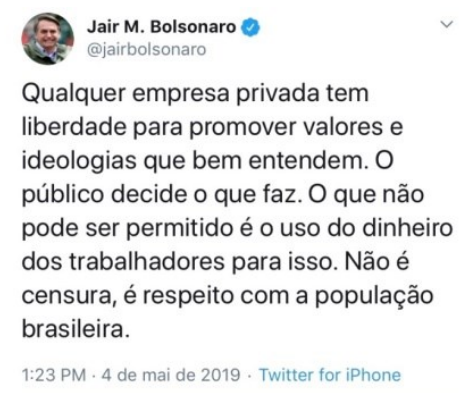

Fonte: Twitter

$\mathrm{Na}$ Figura 6, Bolsonaro afirma "qualquer empresa privada tem liberdade para promover valores e ideologias que bem entendem. O público decide o que faz.". A agência 


\section{Linguagens - Revista de Letras, Artes e Comunicação - ISSN 1981- 9943 \\ Blumenau, v. 15, n. 1, p. 146-166, jan./abr. 2021. \\ DOI: http://dx.doi.org/10.7867/1981-9943.2021v15n1p146-166}

repreendida é uma instituição pública — o Banco do Brasil — e os grupos são minorias raciais e, novamente, sexuais, pois ele vetou a propaganda dessa agência que propaga a diversidade racial e sexual. Primeiramente, é possível notar uma tentativa de neutralidade ideológica - nesse caso, a valoração de um padrão normativo e o cerceamento de sujeitos destituídos - na qual Volóchinov (2018) afirma não existir essa possibilidade, pois signos e significados são, inevitavelmente, carregados por um caráter ideológico e, portanto, trata-se de uma pseudoneutralidade.

Quando o presidente assevera "o público decide o que faz", é importante salientar que Löwy (2000) afirma que as pessoas são constituídas de verdades unilaterais, ou seja, cada sujeito é provindo de um caráter ideológico de acordo com suas relações sociais, culturais, políticas etc. Dessa maneira, o que é certo, verdade, bom para determinado sujeito, pode ser ao contrário para outro. Assim, o público são as pessoas - que são formadas por suas diversidades étnicas; raciais; sexuais; culturais; sociais; políticas.

Além disso, é possível perceber o ato de coação - por causa da censura - quando o presidente afirma "o que não pode ser permitido", ou seja, prevalece à manutenção do status $q u o$, no qual predomina uma ideologia dominante de um líder político conservador, que sinaliza intolerância a diversidades construídas em uma arquitetura argumentativa. Reconhece, inicialmente, liberdade, valores, ideologias para reforçar o contra-argumento que defende a censura e o controle. Como Pennycook (2006) argumenta, ninguém é obrigado a concordar com ninguém, porém é necessária a busca pela compreensão de comportamentos genuínos, ao invés de ignorá-los, ou ainda censurá-los.

\section{CONSIDERAÇÕES FINAIS}

O presente artigo objetivou analisar questões de ideologia que são representadas pelos tweets postados na conta oficial de Bolsonaro. Para isso, inicialmente, os movimentos da Linguística Aplicada foram discutidos, a fim de entender o natural diálogo da LA com outras áreas do conhecimento, tão bem como compreender a importância de seu viés crítico na pósmodernidade. Posteriormente, questões de ideologia e diferentes movimentos históricos, dentre eles o positivismo, o historicismo e o marxismo, foram abordados.

A partir das teorias versadas, foram analisados seis tweets postados na conta oficial do atual presidente da república, Jair Bolsonaro, entre os meses de fevereiro e setembro de 2019, em sua rede social Twitter como foco para as agências; grupos alvos de críticas; conteúdo ideológico e (tentativas) de censuras. 


\section{Linguagens - Revista de Letras, Artes e Comunicação - ISSN 1981- 9943 \\ Blumenau, v. 15, n. 1, p. 146-166, jan./abr. 2021. \\ DOI: http://dx.doi.org/10.7867/1981-9943.2021v15n1p146-166}

A análise da materialidade linguística possibilitou identificar regularidades linguísticas como o uso da modalização. Esse fenômeno da linguagem foi identificado em: "tem que" (Figura 1); “é preciso" (Figura 2); “o que não pode ser permitido" (Figura 6). Essas expressões indicam obrigatoriedade e essa é umas das características do discurso político autoritário e antidemocrático. Outra regularidade é o uso dos verbos "extingue" (Figura 4); "acaba" (Figura 4); e "Anula" (figura 5) que são semanticamente próximos e indicam o sentido de anulação. Embora a Figura 5 seja da manchete do jornal O Globo, houve somente uma modalização do verbo "acabar". Desse modo, novamente, por meio desses termos, um discurso político autoritário e, portanto, não democrático, é caracterizado.

Discursivamente, ressalta-se que sujeitos divergem em suas crenças e opiniões, o que pode gerar uma saudável pluralidade de ideias, entretanto, uma argumentação fundamentada é necessária, ao invés de ignorar e, consequentemente, atacar essas discordâncias (PENNYCOOK, 2006). Apesar de o educador crítico comumente atrair o ódio de sujeitos que estão a favor da manutenção do status quo, como observado ao longo da história (RAJAGOPALAN, 2003), ele tem um papel fundamental na contestação de verdades unilaterais. Sendo assim, percebe-se a importância da visibilidade de diferentes formas de percepção e a busca por uma resistência com relação a círculos históricos viciados (FABRICIO, 2006), como foram demonstradas ao longo dessa pesquisa.

Com base nos resultados, depreende-se o posicionamento ideológico, caracterizado pelo conservadorismo, preconceito e intolerância, do autor dos enunciados, em que ele faz críticas e (tentativas de) de censura a determinadas esferas da sociedade - atores educacionais, membros da sociedade civil e minorias raciais e sexuais - por terem vieses ideológicos divergentes, que são representados por suas diferenças individuais e expressos no seu modo de pensar, viver, sentir e crer. Dessa forma, por meio da análise dos enunciados, foram sinalizadas diferentes ameaças a ordem democrática do Brasil.

Com relação à tentativa de "neutralidade" - que é muito comum em classes dominantes sobre classes dominadas -, é importante ressaltar que ela está ligada a interesses de manutenção do status quo (LÖWY, 2015). Essa premissa, inexistente e infundada, foi encontrada em diferentes momentos no discurso do presidente da república que foi aqui analisado. Desse modo, a luta contra a alienação - como sujeitos conscientes e críticos - é fundamental para que seja possível perpassar uma verdade unilateral (DUARTE; MARTINS, 2013).

Em consequência de uma visão crítica e emancipatória, como discutida anteriormente, pode-se gerar um questionamento: existe a possibilidade de uma mudança ou transformação 
contra uma ordem estabelecida que repreenda - por meio de opressões e censuras minorias de número e/ou "valor", ou sujeitos que estão defronte de um "campo de batalha" por almejarem sociedades mais justas e menos desiguais (LESSA; TONET, 2011)? Os próprios autores respondem a essa pergunta quando argumentam que, numa visão conservadora de mundo, a resposta é não; visto que as organizações e visões sociais dependem do fator histórico e, portanto, uma passividade - mesmo diante do sofrimento alheio - acaba por prevalecer.

Entretanto, os revolucionários sugerem uma utopia - que se trata da busca pela construção de espaços mais democráticos - com direitos igualitários para todos os seres humanos (LÖWY, 2015). Desse modo, mesmo que o percurso seja longo e desafiador, há espaço para que se avance e haja contribuições na redução desse fardo que grupos destituídos carregam ao longo de suas vidas e histórias. Portanto, essa resistência (ou ruptura) — que se almejou buscar e contribuir, por meio desse estudo — é provindo de um olhar crítico - e sustentada pelas teorias de LA e questões de ideologia.

\section{REFERÊNCIAS}

BRASIL. [Constituição (1988)]. Constituição da República Federativa do Brasil de 1988. Brasília, DF: Presidência da república, [2016]. Disponível em:

http://www.planalto.gov.br/ccivil_03/Constituicao/Constituicao.htm. Acesso em: 1 jan. 2017.

DUARTE, N.; MARTINS, L. M. As contribuições de Aleksei Nikolaevich Leontiev para o entendimento da relação entre educação e cultura em tempos de relativismo pós-moderno. In: FERRO, O. M. R.; LOPES, Z. A. L. (Org.). Educação e cultura: lições históricas do universo pantaneiro. Campo Grande: UFMS, 2013. p. 49-74.

FABRÍCIO, B. F. Linguística aplicada como espaço de "desaprendizagem": redescrições em curso. In: MOITA LOPES, L. P. (Org.). Por uma linguística aplicada INdisciplinar. São Paulo: Parábola, 2006.

GERALDI, J. W. Ancoragens: Estudos Bakhtinianos. São Carlos: Pedro \& João, 2010.

GREENHOW, C.; GLEASON, B. Twitteracy: Tweeting as a new Literacy Practice. The Educational Forum, vol. 76, p. 464-478, 2012.

KUMARAVADIVELU, B. A linguística aplicada na era da globalização. In: MOITA LOPES, L. P. (Org.). Por uma linguística aplicada INdisciplinar. São Paulo: Parábola, 2006.

LESSA, S.; TONET, I. Introdução à filosofia de Marx. 2. ed. São Paulo: Expressão Popular, 2011. 
LÖWY, M. Ideologias e ciência social: elementos para uma análise marxista. 20. ed. São Paulo: Cortez, 2015.

LÖWY, M. As aventuras de Karl Marx contra o Barão de Münchhausen: marxismo e positivismo na sociologia do conhecimento. 7. ed. São Paulo: Cortez, 2000.

LYOTARD, J.F. A condição pós-moderna. Tradução de Ricardo Corrêa Barbosa. 17. ed. Rio de Janeiro: José Olympio, 2018.

MEDVIÉDEV, P. N. O método formal nos estudos literários: introdução crítica a uma poética sociológica. Tradução de Sheila Camargo Grillo e Ekaterina Vólkova Américo. São Paulo: Contexto, 2012.

MENEZES, V.; SILVA, M. M.; GOMES, I. F. Sessenta anos de linguística aplicada: de onde viemos e para onde vamos. In: PEREIRA, R. C.; ROCA, P. Linguística aplicada: um caminho com diferentes acessos. São Paulo: Contexto, 2009. p. 25-50.

MOITA LOPES, L.P. Uma Linguística aplicada mestiça e ideológica: interrogando o campo do linguista aplicado. In: MOITA LOPES, L. P. (Org.). Por uma linguística aplicada INdisciplinar. São Paulo: Parábola, 2006.

MOITA LOPES, L. P. Da aplicação de linguística à linguística aplicada indisciplinar. In: PEREIRA, R. C.; ROCA, P. (Org.). Linguística aplicada: um caminho com diferentes acessos. São Paulo: Contexto, 2009. p.11-24.

NEVES, M. H. Gramática de usos. 2. Ed. São Paulo: Unesp, 2011.

PENNYCOOK, A. Uma linguística aplicada transgressiva. In: MOITA LOPES, L. P. (Org.). Por uma linguística aplicada INdisciplinar. São Paulo: Parábola, 2006.

PINTO, C. R. J. Elementos para uma análise de discurso político. Revista Barbarói. Santa Cruz do Sul, n. 24, p. 78-109, 2006.

RAJAGOPALAN, K. O conceito de identidade na linguística: é chegada a hora para uma reconsideração radical? In: SIGNORINI (Ed.). Lingua(gem) e identidade. Campinas: Mercado de Letras, 1998, p.21-40.

RAJAGOPALAN, K. Por uma linguística crítica: linguagem, identidade e a questão ética. São Paulo: Parábola Editorial, 2003.

ROJO, R. Gêneros do discurso e gêneros textuais: questões teóricas e aplicadas. In: MEURER, J. L.; BONINI, A.; MOTTA-ROTH, D. (Org.), Gêneros: teorias, métodos, debates. São Paulo: Parábola, 2005.

SIGNORINI, I. Lingua(gem) e identidade. Campinas: Mercado de Letras, 1998.

STORTO, L. J.; ZANARDI, R.C. Análise discursiva de governo coloca ideologia de gênero no ENEM do pastor Silas Malafaia: discurso político, da natureza e de ódio. Linguagem em (dis)curso (online), v. 19, p. 383-400, 2019. 
VOLÓCHINOV, V. Marxismo e filosofia da linguagem: problemas fundamentais do método sociológico na ciência da linguagem. Tradução, notas e glossário de Sheila Grillo e Ekaterina Vólkova Américo. 2. ed. São Paulo: 34, 2018.

Submetido: $11 / 11 / 2020$ Aceito: $21 / 04 / 2021$ 